\title{
LA INCIDENCIA DEL DERECHO COMUNITARIO SOBRE LAS RELACIONES ESTADO-REGIONES EN ITALIA
}

\author{
TANIA GROPPI \\ Profesora Asociada de Derecho Constitucional. \\ Universidad de Siena (Italia)
}




\section{SUMARIO}

1. INTRODUCCIÓN: ¿EL DERECHO COMUNITARIO ES INDIFERENTE A LA DISPOSICIÓN TERRITORIAL DE LOS ESTADOS MIEMBROS? 2. LA ACTUACIÓN DEL DERECHO COMUNITARIO EN MATERIAS REgIONALES: LA EVOLUCIÓN DEL CUADRo Normativo. 3. A LA BÚSQUEDA DE UN DIFICIL EQUILIBRIO ENTRE EXIGENCIAS DE LAS AUTONOMIAS REGIONALES Y UNIDAD DE LA RESPONSABILIDAD ESTATAL: LOS PODERES ESTATALES REPRESIVOS $Y$ SUSTITUTIVOS EN LA JURISPRUDENCIA CONSTITUCIONAL. 4. LA ALTERACIÓN DEL REPARTO CONSTITUCIONAL DE LAS COMPETENCIAS POR PARTE DE LAS NORMAS COMUNITARIAS. 5. FORMAS DE PARTICIPACIÓN (DIRECTA E INDIRECTA) DE LAS REGIONES EN LA FORMACIÓN DE LA VOLUNTAD COMUNITARIA. 


\title{
LA INCIDENCIA DEL DERECHO COMUNITARIO SOBRE LAS RELACIONES ESTADO-REGIONES EN ITALIA*
}

\author{
TANIA GROPPI \\ Profesora Asociada del Derecho Constitucional. \\ Universidad de Siena
}

1. INTRODUCCIÓN: ¿EL DERECHO COMUNITARIO ES INDIFERENTE A LA DISPOSICIÓN TERRITORIAL DE LOS ESTADOS MIEMBROS?

La impronta internacionalista que ha caracterizado desde el inicio a la Comunidad europea, nacida como asociación de Estados, la ha mantenido por mucho tiempo indiferente a la estructura interna, centralista, federal, o regional, de los Estados miembros'.

Las múltiples solicitudes surgidas en sede institucional, sobre todo en el ámbito del Parlamento europeo, a "abrir» la Comunidad a las regiones han permanecido por largo tiempo como letra muerta ${ }^{2}$.

* Traducción del italiano al castellano realizada por el Dr. D. Carlos Vidal Prado, Profesor Asociado del Departamento de Derecho Constitucional de la UNED.

1 En este sentido, ver, recientemente, TORCHIA, L., Regione e Unione europea: temi e problemi, en Le regioni, 2000, 495 ss.; CARTABIA,M.; WEILER, J.H.H.: L'Italia in Europa. Profili istituzionali e costituzionali, Bolonia, 2000, 199 ss.

2 Véanse las resoluciones que se han sucedido en los años posteriores a 1977, así como la declaración común del Consejo, de la Comisión y del Parlamento de 19 de junio de 1984 sobre la exigencia de asociar las regiones al proceso de toma de decisiones comunitario y la "Carta comunitaria de la regionalización" del 17 de noviembre de 1988 . 
Aunque el "regionalismo económico" no ha estado nunca ausente del cuadro comunitario, en el sentido de que la Comunidad ha tenido siempre una política regional propia destinada a favorecer el desarrollo de las áreas más pobres, tales intervenciones eran realizadas en el pasado directamente por las instituciones comunitarias o por los Estados miembros, mientras que las regiones se consideraban esencialmente como áreas de referencia con caracteres socioeconómicos homogéneos ${ }^{3}$.

Esta orientación cambia, como es sabido, en el curso de los años ochenta, con ocasión de la elaboración de los programas integrados mediterráneos (PIM), por los cuales las normas comunitarias (Reglamento 2088/85/CEE) preveían una participación directa de las regiones interesadas en las acciones comunitarias -la llamada partnership-y les atribuían competencias inéditas, dando inicio a una tendencia continuada también con ocasión de la reforma de los fondos estructurales (Reglamento 2052/88/CEE).

Pero es sobre todo el Tratado de Maastricht el que contiene una serie de previsiones cuyo contenido hace difícil hoy continuar repitiendo que "los tratados son ciegos en relación con la articulación interna de los Estados miembros" (lpsen). La introducción del principio de subsidiariedad, que no parece que valga sólo en el ámbito de las relaciones entre Estados y Unión europea, sino también entre Estados y entes autónomos territoriales; la modificación de la composición del Consejo de Ministros (art. 203, ex art. 146) en el sentido de no exigir ya la representación oficial del gobierno nacional, consintiendo por tanto también la presencia de representantes regionales; la creación del Comité de las Regiones, son todos aspectos que muestran una atención renovada por el fenómeno regional, hasta el punto de que algunos autores han descrito una verdadera y propia rearticulación de la Comunidad sobre tres niveles ${ }^{4}$.

No obstante estos intentos de revalorización de las entidades locales en el contexto europeo, permanece firme el principio, repeti-

$3 \quad$ Ilustrativo de esta situación puede considerarse también el art. $130 \mathrm{~A} \mathrm{y}$ ss., ahora art. 158 y ss., introducido en el Tratado con el Acta Única Europea de 1986, que pretendia reducir la divergencia entre las regiones europeas.

4 CHITI, M.P.: Regioni e integrazione europea, en Reg. gov. loc., 1994, 547 ss.; ld., Casi e materiali di diritto pubblico comunitario, Turín, 1995, 305 ss. Recientemente, ver D'ATENA, A.: // doppio intreccio federale: le regioni nell'Unione europea, en Le regioni, 1998, 1401 ss.; Id., II difficile cammino europeo delle regioni italiane, en Le regioni, 2000, 555 ss. 
damente afirmado por el Tribunal de Justicia, según el cual el Estado es el único responsable del cumplimiento (jy del incumplimiento!) de las obligaciones comunitarias: éste no puede invocar, a fin de justificar la inobservancia de disposiciones comunitarias, las garantías previstas por el propio ordenamiento para las autonomías regionales ${ }^{5}$. Lo que tiene relevancia, para el Tribunal de Justicia, es que se asegure a su tiempo y correctamente el cumplimiento de las obligaciones comunitarias por parte de todos los Estados miembros, mientras que es indiferente la concreción del órgano o del sujeto sobre el cual recaen tales obligaciones en función de la organización interna de cada Estado $^{6}$.

Esta situación de la Comunidad no carece de repercusiones en el ordenamiento italiano: si por muchos aspectos el ordenamiento comunitario, en sus relaciones con el nacional, se ha venido caracterizando por notas que lo diferencian del derecho internacional, la impronta internacionalista, junto con la unidad de la responsabilidad (estatal), ha permanecido inalterada con respecto al papel de las regiones.

5 Véanse, en este sentido, la sentencia del Tribunal de Justicia de 27 de marzo de 1984 (causa C-169/82), que condena a Italia por el incumplimiento de las obligaciones del Tratado, en el sentido del entonces art. 169, como consecuencia de leyes de la Región siciliana que colisionaban con Reglamentos comunitarios, así como la sentencia de 15 de octubre de 1986 (causa C-168/85), según la cual el mantenimiento en vigor de procedimientos incompatibles con el Tratado constituye una transgresión de las obligaciones impuestas por el mismo Tratado. Otras referencias a la jurisprudencia comunitaria y algunas consideraciones críticas pueden verse en GuzzetTA, G.: Costituzione e regolamenti comunitari, Milán, 1994, 171. Ha sido sin embargo recordado que uen cuarenta años de integración europea (hasta el 30 de noviembre de 1990), se pueden encontrar apenas 23 sentencias que "condenan" a los estados por violaciones originadas por regiones y por otros poderes autónomos como las provincias y los ayuntamientos»: así, Mangas Marín, A.: Comunità autonome e diritto comunitario in Spagna: un approccio generale, en Le regioni, 1992, 664 ss., en particular 683.

6 CARTABIA, M.; OnIDA, V: Le regioni e la Comunità europea, en Trattato di diritto amministrativo, dirigido por CHITI, M.P. e Greco, G., Milán, 1997, 605. El Tribunal de Justicia ha afirmado por otra parte que regiones $y$ estados miembros de la federación son responsables, como todas las otras administraciones públicas, por los daños causados a los individuos como consecuencia de violación de derecho comunitario: ver sentencia de 1 junio de 1999 (causa 302/97). Además, en años más recientes, el Tribunal de primera instancia ha reconocido a las regiones italianas, asi como a otros entes infraestatales, la legitimación para recurrir contra decisiones en materia de ayudas públicas: ver la sentencia de 15 junio de 1999, en la causa T-288/97, sobre la cual puede confrontarse O.Porchia, Le regioni italiane davanti al Tribunale di primo grado: il riconoscimento della legittimazione attiva in materia di aiuti pubblici, en Dir. pubb. comp. eur., 1999, 1674 ss. 
Las relaciones centro-periferia en las materias afectadas por el derecho comunitario han sido desde el inicio consideradas con un carácter de especialidad, así como, más ampliamente, las relativas a las relaciones internacionales, recayendo en un ámbito, el poder exterior, en el cual los estados regionales continúan diferenciándose de modo relevante de los federales (sobre todo si han nacido por agregación)?.

El largo "camino comunitario" de las regiones italianas (de las especiales primero, y después, desde 1970, de las ordinarias) ha estado dirigido a reducir al mínimo las alteraciones de las relaciones entre Estado y regiones derivadas de la titularidad principal por parte del Estado de la responsabilidad comunitaria: a reducir, podríamos decir, la "especialidad comunitaria", haciendo posible la re-expansión también a los sectores afectados por el derecho comunitario de las normales reglas competenciales. Tal recorrido - desarrollado esencialmente, ante el silencio de la Constitución ${ }^{8}$, a través de la evolución de la legislación estatal, respecto de la cual la jurisprudencia constitucional ha asumido una posición casi ratificatoria, de racionalización de lo existente - ha afectado tanto a la fase descendente, de la actuación del derecho comunitario en las materias regionales, como a la ascendente, de la participación regional en la adopción de las decisiones comunitarias y de las decisiones estatales de relevancia comunitaria, según un proceso de "recuperación" de competencias y de presencia regional. Este proceso no resulta diferente, por otra parte, del verificado de modo más general en lo que se refiere a las relaciones con el ordenamiento internacional ${ }^{9}$.

Junto a la tendencia a reconducir las áreas afectadas por el derecho comunitario al marco habitual de relaciones Estado-regiones, se

7 Ver, recientemente, Palermo, F.: I/ potere estero delle regioni. Ricostruzione in chiave comparata di un potere interno alla costituzione italiana, Padua, 1999, en particular 74 ss., que reconduce el poder exterior de los Estados miembros en las federaciones nacidas por unión a un "residuo contractual». Para un replanteamiento de las categorías tradicionales de Estado federal y regional, ver Reposo, A., Profili dello stato autonomico. Federalismo e regionalismo, Turín, 2000; asi como GROPPI, T.: Rigidità e mutamento costituzionale negli stati federali, edición provisional, Siena, 2000.

8 Los estatutos de las regiones especiales contienen por su parte sólo una referencia a las "obligaciones internacionales" como limite a la potestad legislativa primaria o exclusiva: artículos $14,3,4,4$ y 2 respectivamente de los estatutos de Sicilia, Cerdeña, Trentino-Alto Adige, Friuli-Venecia Giulia y Valle de Aosta.

9 Aunque este último proceso se ha desarrollado más por vía jurisprudencial que normativa: PALERMo, F.: Il potere estero delle regioni, op. cit., 57 ss. 
encuentra también la de la difusión, fuera de tal campo, de instrumentos nacidos para satisfacer las exigencias comunitarias: tendencia, esta última, que contribuye también, aunque según un proceso inverso respecto a la primera, a la reducción de la "especialidad comunitaria» producida al final de los años noventa ${ }^{10}$.

\section{LA ACTUACIÓN DEL DERECHO COMUNITARIO EN MATERIAS REGIONALES: LA EVOLUCIÓN DEL CUADRO NORMATIVO}

También en las relaciones Estado-regiones, así como en muchos otros aspectos institucionales (piénsese en las relaciones gobierno-parlamento), la pertenencia de Italia a la Comunidad europea ha incidido profundamente sobre la disposición organizativa interna: no sólo importantes materias atribuidas a la Comunidad son al mismo tiempo materias que la Constitución califica como de competencia, legislativa y administrativa, de las regiones (la agricultura, el medio ambiente, la formación profesional, la cultura, las obras públicas), sino que además la expansión de la esfera de atribuciones regionales, puesta en marcha en Italia desde la ley n. 59 de 1997, especialmente sobre el plano administrativo, hace que las interferencias sean siempre más amplias y probables.

En su papel de autoridad administrativa, las regiones, como todas las autoridades públicas, están llamadas a asegurar la aplicación del derecho comunitario "directamente aplicable" (self-executing)" . Este "poder-deber" de las regiones ha encontrado reconocimiento por parte del Estado desde el Decreto del presidente de la República (d.P.R.) n. .616 de 1977, con base en el cual (art. 6) las regiones eran Ilamadas a ejecutar en vía administrativa los reglamentos comunitarios (noción después extendida a comprender también las directivas dotadas de

10 Esta se refiere principalmente al poder gubernamental de sustitución de la administración regional que incumple, poder que, previsto en el ámbito comunitario por el art. 6 del Decreto del presidente de la República n. 616 de 1977, ha sido extendido a la generalidad de las funciones "conferidas" por el Estado a las regiones por medio del art. 5 del Decreto legislativo n. 112 de 1998, así como a la posibilidad para el gobierno de adoptar en vía meramente supletoria reglamentos en materia regional; este último poder, previsto por el art. 9 , apartado 4 , de la ley n. 86 de 1989 para la ejecución de obligaciones comunitarias, fue extendido por la ley anual de simplificación para 1999 (ley de 24 de noviembre de 2000, n.o 340, art. 1) a todos los sectores investidos por la simplificación administrativa.

11 Así el Tribunal de Justicia, sentencia de 22 de junio de 1989, Costanzo, y Corte costituzionale, sentencia n. 389 de 1989. 
efectos directos). El Estado ha mantenido en relación con la actividad administrativa desarrollada por las regiones en materias afectadas por el derecho comunitario la función de "dirección y coordinación", que se ejercitará cuando el cumplimiento de las obligaciones comunitarias afecte a exigencias de carácter unitario sobre todo el territorio nacional (art. 9, apartado 5, ley n. ${ }^{\circ} 8$ de 1989). Tal función es desempeñada por el Gobierno, hoy (art. 8 de la ley $n .{ }^{\circ} 59$, de 1997) previo entendimiento con la región interesada $o$, en caso de actuación que afecte a más regiones, con la Conferencia Estado-regiones, órgano mixto de participación de las regiones en la actividad estatal.

En cuanto responsable frente a la Comunidad, el Estado es además titular del poder sustitutivo, que se ejercitará según un complejo procedimiento introducido para garantizar la autonomia regional (art. 6 d.P.R. $n . \circ 161$, de 1977 y art. 11 de la ley $n . .86$ de 1989). El inicio del procedimiento en caso de comprobada inactividad de los órganos regionales que comporte incumplimiento de las obligaciones comunitarias, compete, de oficio, al Ministro para las políticas comunitarias y al Ministro de asuntos regionales; el Consejo de ministros, por tanto, oída la región interesada y la comisión parlamentaria para las cuestiones regionales, asigna una fecha límite para proveer; concluido el plazo, el Consejo de Ministros puede adoptar los procedimientos sustitutivos, entre los cuales figura el nombramiento de una comisión especifica.

Más complejo es el discurso relativo a la ejecución en vía legislativa del derecho comunitario. En un primer momento, efectivamente (d.P.R. n. 4 de 1972), la existencia de una responsabilidad del Estado hacia el respeto de las obligaciones internacionales había proporcionado el argumento para centralizar toda competencia en primer lugar en los órganos estatales: la existencia de una obligación comunitaria producía el efecto de sustraer la correspondiente competencia a las regiones, puesto que el cumplimiento de aquella obligación debía provenir solamente del Estado. Posteriormente (art. 6 d.P.R. n. 0616 de 1977) se llevó a cabo una primera apertura en el sentido de consentir la ejecución de las directivas comunitarias a través de leyes regionales, pero sólo si ya habían sido recibidas por el Estado con una ley que individuaba las normas de principio y asimismo establecía una disciplina reguladora de detalle, que cedería ante las sucesivas leyes regionales. Los inconvenientes que se derivaban de la necesaria interposición estatal eran muchos ${ }^{12}$. La posibilidad para las regiones de legislar esta-

12 Se ha hablado, al respecto, de una "sustitución preventiva»: MARTINES, T.; Ruggeri, A.: Lineamenti di diritto regionale, Milán, 2000, 210. Ver las observa- 
ba condicionada a la existencia de una ley estatal: el no poco frecuente incumplimiento estatal se transformaba en incumplimiento regional. Además, la presencia de una normativa estatal de principio, siempre necesariamente acompañada de normas de detalle, hacía muy difícil distinguir los dos tipos de disciplina reguladora e individuar con precisión el ámbito regional.

Los sucesivos desarrollos se han llevado a cabo en el sentido de consentir a las regiones legislar directamente en ejecución de las normas comunitarias, sin la intermediación del Estado. Tal potestad fue reconocida ya en 1987 a las regiones de estatuto especial, de modo limitado a las materias en las cuales aquéllas están dotadas de competencia legislativa exclusiva (ley n.o 183 de 1987, art. 113), y en 1998 a las regiones de estatuto ordinario (ley n. -128 de 1998, que modifica el art. 9 de la ley $n .986$ de 1989) ${ }^{13}$.

Por tanto, hoy, la ejecución del derecho comunitario en las materias regionales tiene lugar según el habitual esquema que disciplina las relaciones entre ley estatal y ley regional ${ }^{14}$.

En las materias en las cuales las regiones tienen potestad legislativa concurrente ${ }^{15}$, pueden legislar también en ausencia de una previa ley

ciones críticas de CARETTI, P.: Ordinamento comunitario e autonomia regionale, Milán, 1979, 179 ss., y de D'ATENA, A.: Le regioni italiane e la Comunità europea, Milán, 1981,70 ss.

13 El art. 9 de la ley $n . .96$ de 1989 habia introducido para las regiones ordinarias una solución híbrida y muy criticada, que se mantuvo en vigor hasta 1998 , según la cual las regiones podian ejecutar las directivas después de la entrada en vigor de la primera "ley comunitaria" sucesiva a la notificación de la directiva, queriéndose de este modo dejar al Estado una posibilidad de prevenir la intervención regional, con ocasión de la anual ley comunitaria, prevista precisaménte para eliminar demoras en la recepción del derecho comunitario. Sobre la ley comunitaria, vid. infra.

14 Las leyes regionales deben indicar, según el apartado 2-bis del art. 9 de la ley n. 96 de 1989, introducido en 1998, el número de las concretas directivas ejecutadas. Los extremos identificativos de las mismas leyes (número y fecha de publicación) son además comunicados al Departamento para la coordinación de las políticas comunitarias instituido bajo la Presidencia del Consejo de Ministros.

15 Es éste el principal tipo de competencia legislativa de las quince regiones ordinarias, con base en el art. 117 de la Constitución. También las cinco regiones especiales (con excepción del Valle de Aosta) tienen potestad legislativa concurrente en algunas materias indicadas en los propios estatutos. Más allá del nombre, este tipo de potestad legislativa no tiene nada en común con la competencia concurrente del art. 74 de la Grundgesetz, acercándose si acaso a la del art. 75, por la cual el Bund puede emanar Rahmengesetzgebung. Las leyes regionales deben efectivamente respetar los principios fundamentales establecidos por las leyes del Es- 
estatal de principio. Por lo demás, los principios derivados de la ley estatal, que deberian ser expresamente indicados por ésta, no pueden ser derogados por las regiones y prevalecen sobre cualquier norma regional incompatible. En las materias de competencia legislativa exclusiva, las regiones de estatuto especial deben respetar únicamente los principios de las leyes estatales que, según los propios estatutos, son idóneos para vincular tal tipo de competencia ${ }^{16}$ (art. 9, apartado 3, ley n. 86 de 1989).

Sin embargo, este punto de llegada de la larga evolución normativa no ha logrado trasladar las relaciones Estado-regiones en la ejecución del derecho comunitario a una situación de normalidad, al menos desde dos puntos de vista: de un lado, efectivamente, la responsabilidad comunitaria del Estado requiere que éste disponga de instrumentos (represivos o sustitutivos y supletorios) para hacer frente al eventual incumplimiento regional; por otro, el mismo derecho comunitario puede comportar una alteración del reparto interno de atribuciones o un vaciamiento de las competencias regionales.

\section{A LA BÚSOUEDA DE UN DIFICIL EQUILIBRIO \\ ENTRE EXIGENCIAS DE LAS AUTONOMÍAS REGIONALES Y UNIDAD DE LA RESPONSABILIDAD ESTATAL: \\ LOS PODERES ESTATALES REPRESIVOS Y SUSTITUTIVOS EN LA JURISPRUDENCIA CONSTITUCIONAL}

La jurisprudencia constitucional sobre la ejecución del derecho comunitario en las materias regionales parece que ha alcanzado una posición suficientemente definida.

Según la Corte, "la ejecución en los Estados miembros de las normas comunitarias debe tener presente la estructura (centralista, descentralizada, federal) de cada uno de ellos, de modo que Italia está habilitada, además de impulsada por su propio derecho constitucional, a respetar su fundamental disposición regional. Por tanto, donde la

tado en cada materia. En ausencia de leyes estatales de principio (leyes «quadron o leyes "cornice") la jurisprudencia constitucional ha establecido que las regiones pueden en todo caso legislar, respetando los principios que se derivan de la legislación estatal, $y$ adecuándose en el futuro a lo dispuesto en las leyes marco que sean aplicables. (N. del T.: He preferido respetar los términos italianos de leyes quadro o leyes cornice, que equivalen en castellano a las leyes marco).

${ }_{16}$ Se trata de los principios generales del ordenamiento juridico, de las normas fundamentales de las grandes reformas económico-sociales, de las obligaciones internacionales. 
aplicación o la ejecución de una norma comunitaria ponga en cuestión una competencia legislativa o administrativa que afecte a un sujeto titular de autonomía constitucional, no puede dudarse que (...) normalmente a ese sujeto corresponde actuar en aplicación o en ejecución, en el ámbito de las habituales relaciones con el Estado y de los límites constitucionalmente previstos en las diversas materias de competencia regional (...). Sin embargo, puesto que de la ejecución del derecho comunitario en el ordenamiento interno, frente a la Comunidad Europea, es responsable íntegra y unitariamente el Estado (...), a éste - permaneciendo inalterada, según lo que acabamos de decir, la competencia en "primera instancia" de las regiones y provincias autónomascorresponde una competencia, desde el punto de vista lógico, de "segunda instancia", dirigida a posibilitar al Estado que no se encuentre impotente frente a violaciones de derecho comunitario derivadas de actuaciones positivas $u$ omisivas de los sujetos dotados de autonomía constitucional. Los instrumentos consisten no en la invocación de competencias a favor del Estado, sino en intervenciones represivas o sustitutivas o supletorias -estas últimas incluso preventivas, pero cesantes ante la activación de los poderes regionales y provinciales normalmente competentes - respecto a violaciones o carencias en la actuación o en la ejecución de las normas comunitarias por parte de las regiones" (sentencia n.․ 126 de 1996).

De este modo ha sido redimensionada la jurisprudencia precedente, que partía del reconocimiento de que el Estado es el destinatario de la obligación prevista por el art. 249 del Tratado (ex 189) para remitir a los órganos centrales la apreciación de las exigencias unitarias en la ejecución de la normativa comunitaria, hasta el punto de sustraer a las regiones completos sectores competenciales ${ }^{17}$.

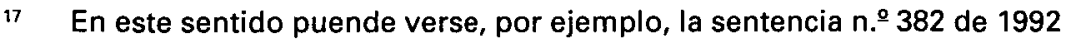
y la sentencia n. 9632 de 1988 , y, más en general, la jurisprudencia que reconoce legítimas las intervenciones estatales en materia regional, en cuanto que el Estado es el único responsable del cumplimiento de las obligaciones comunitarias. Sobre este tema, ver CARETTI, P.; StrozzI, G.: Luci ed ombre nella più recente giurisprudenza costituzionale in materia di adempimento agli obblighi comunitari, en Le regioni, 1988, 196 ss., así como CocozzA, F.: Regioni e diritto comunitario nella giurisprudenza della corte costituzionale, en Le regioni, 1992, 620 ss., en particular 648, que habla de jurisprudencia "pretoria", que "ha considerado el valor de la autonomía local siempre recesivo respecto al otro valor de la obligación internacional y de la consiguiente responsabilidad estatal". En sentido contrario, ver la (aislada) sentencia n.o 124 de 1990, donde se afirma que la región es uente destinatario de las obligaciones internacionales del Estado, y es tarea suya dar ejecución de éstas a nivel local, en el ámbito de la propia competencia». 
La exigencia de garantizar el respeto al derecho comunitario, incluso por parte de las regiones, ha comportado la determinación, sea por vía legislativa o jurisprudencial, de instrumentos represivos «especiales".

En referencia a la actividad administrativa de las regiones, la "especialidad" se concreta en cuanto que la generalizada abolición (con la sola excepción de los reglamentos) del control gubernativo preventivo de legitimidad sobre los actos administrativos regionales no ha afectado a "los actos que constituyen cumplimiento de las obligaciones que se derivan de la pertenencia de Italia a la Unión Europea" (art. 17, apartado 32, ley n. .127 de 1997).

Con relación a la potestad legislativa, la jurisprudencia constitucional ha reconocido al Estado la posibilidad de impugnar las leyes regionales contradictorias con el derecho comunitario, en cuanto que de ello derivaría una violación; indirecta, del art. 11 de la Constitución (la disposición en la cual se proclama el fundamento de la eficacia directa de las normas comunitarias en el ordenamiento italiano). Tal jurisprudencia constituye una derogación del régimen normal de relaciones entre fuentes primarias italianas y derecho comunitario, basado en la no aplicación por parte del juez común de la normativa nacional que esté en contraste con la comunitaria: tal contraste no da lugar, según jurisprudencia ya consolidada (a partir de la sentencia n. ${ }^{170}$ de 1984) a un vicio de legitimidad constitucional.

La posibilidad para el Estado de impugnar en vía directa ante la Corte Constitucional las normas regionales en conflicto con las comunitarias (sentencia n. ${ }^{\circ} 384$ de 1994) ha sido ligada al carácter preventivo de tal tipo de juicio, que impediría poder encontrar solución a la cuestión ante un juez común, pero ha sido justificada sobre todo en nombre de la responsabilidad comunitaria del Estado ${ }^{18}$. Por otra parte, en un segundo momento (sentencia n. 94 de 1995) tal posibilidad de impugnación directa ha sido reconocida asimismo a las regiones en relación con las leyes estatales: también en este caso, efectivamente, aun tratándose de un juicio sucesivo, no existe un juez a quo habilitado para no aplicar la norma interna.

Si bien esta orientación que acabamos de exponer, sobre la cual se ha asentado la jurisprudencia sucesiva, reduce el peso de la res-

18 Este punto de vista ha sido puesto de manifiesto por Pizzorusso, A.: Lo stato italiano è chiamato a rispondere delle violazioni regionali ai trattati $U E$, en Guida al diritto, 21 de enero de 1995, 54 ss. 
ponsabilidad comunitaria del Estado al justificar el recurso principal por violación de normas comunitarias, y tanto el Gobierno como las regiones están ya habilitados para recurrir a la Corte Constitucional por violación del derecho comunitario, la solución a la que aquí se ha llegado, independientemente de las razones subyacentes, proporciona en todo caso a los aparatos centrales un importante instrumento "represivo" en relación con las leyes regionales.

Además, le es reconocida al Estado la titularidad de poderes "sustitutivos y supletorios», frente a la inercia regional. En el campo administrativo estos poderes sustitutivos son, como se ha apuntado, puntualmente regulados incluso sobre un plano procedimental. En caso de ausencia de ejercicio de la potestad legislativa regional, por el contrario, se trata generalmente de intervenciones normativas supletorias, destinadas a permanecer en vigor hasta el momento en que la región utiliza la propia potestad legislativa. Si bien la intervención estatal debe revestir normalmente la forma de ley, conforme a la opinión según la cual en materias de competencia regional existe una reserva de ley, la ley n. 986 de 1989 (art. 9, apartado 4, y artículo 4, apartado 3) prevé que, en ausencia de normas regionales de ejecución, se apliquen, en vía supletoria, incluso las normas reglamentarias del Estado adoptadas sobre la base de la misma ley $n . .86$ de 1989, en ejecución del derecho comunitario.

La Corte Constitucional, frecuentemente rigurosa en la defensa de la esfera regional frente a la intervención de reglamentos gubernamentales, incluso si son supletorios y ceden ante la norma regional, ha reconocido sin embargo la legitimidad de reglamentos del Gobierno que intervienen en materia regional con el fin de dar ejecución al derecho comunitario. Tales reglamentos encuentran sin embargo el límite del principio de legalidad ${ }^{19}$, en el sentido de que cuando pretendan,

19 La sentencia n. $\stackrel{425}{4}$ de 1999 afirma expresamente que «la ejecución comunitaria no es un passepourt que permite al Estado vincular a las autonomías regionales $\vee$ provinciales sin respetar los principios de la propia actividad normativa. También en la adopción de la normativa de ejecución comunitaria, el reglamento estatal -más allá de los casos de reserva de ley previstos en la Constitución- encuentra el límite del principio de legalidad. Tal principio que, como numerosas veces y desde diversos puntos de vista esta Corte ha reconocido, domina las relaciones entre el Estado mismo y las Regiones y las Provincias autónomas, constituye un aspecto de la misma posición que estas últimas están habilitadas para defender en el juicio constitucional (entre las últimas, sentencias nn. 169 de 1999, 250 de 1996, 278 de 1993)». Ver en sentido crítico GuzzETTA, G.: Regolamenti statali a carattere suppletivo e competenze regionali: dalla "decostituzionalizzazione" alla "de- 
incluso aunque fuese en vía supletoria, imponerse directamente a las regiones, deben poderse basar sobre "un fundamento legislativo que vincule y dirija las opciones del gobierno", fundamento que por lo demás las mismas directivas comunitarias que el gobierno está autorizado por la ley para ejecutar contribuyen a determinar (sentencia n. 425 de 1999) ${ }^{20}$. Recapitulando, la Corte ha afirmado que "bajo el perfil del respeto hacia las competencias regionales y provinciales, la ejecución reglamentaria de directivas comunitarias es admisible en cuanto las normas ejecutivas cedan en su aplicación frente a las diversas opciones normativas regionales y provinciales, en los límites en los cuales éstas sean constitucional y estatutariamente admisibles; bajo el perfil del respeto al principio de legalidad en las relaciones entre Estado, Regiones y Provincias autónomas, es admisible en tanto en cuanto el reglamento no vincule a éstos más allá de cuanto se derive de las obligaciones comunitarias y los poderes que prevé se inserten en tareas ya confiadas en vía general de modo preferente a las autoridades consideradas".

En definitiva, si normalmente las relaciones Estado-regiones implican casi siempre una intervención del Parlamento italiano (bien para señalar los principios fundamentales, bien para fijar, en nombre del principio de legalidad sustancial, criterios y principios que el gobierno deberá seguir en el ejercicio de la función de dirección y coordinación), en materia comunitaria tal intervención puede reducirse a la mera autorización al gobierno para ejecutar el derecho comunitario en vía reglamentaria, en tanto que los principios y criterios que el mismo debe seguir pueden venir determinados a nivel comunitario: esto como ulterior testimonio de la permanencia de la "especialidad comunitaria».

legificazione" dell'autonomia territoriale in nome del diritto comunitario, en Giur. cost., 1999, 3746 ss. Muestra el aprecio por el esfuerzo reconstructivo de la Corte CARETTI, P.: La Corte aggiunge un ulteriore tassello al mosaico dei rapporti Stato-regioni in attuazione del diritto comunitario, en Le regioni, 2000, 435 ss.

20 La Corte había sido requerida por algunos recursos regionales a decidir un conflicto de atribución surgido como consecuencia del d. P. R. de 8 de septiembre de 1997, n. 957 (Reglamento relativo a la ejecución de la directiva 92/43/CEE sobre la conservación de los habitats naturales y seminaturales, asi como de la flora y de la fauna selváticas). La Corte ha declarado que compete al Estado dar ejecución a la directiva 92/43/CEE del Consejo de 24 de marzo de 1992, sobre la conservación de los habitats naturales y seminaturales, asi como de la flora y de la fauna selváticas. Tal reglamento, adoptado también para hacer frente a un procedimiento de incumplimiento ante el Tribunal de Justicia, sobre la base de la autorización contenida en el art. 4 de la ley de 22 de febrero de 1994, n. $¹ 46$, según el procedimiento establecido por el art. 4 de la ley $n .-86$ de 1989, ha sido considerado como respetuoso con el principio de legalidad. 


\section{LA ALTERACIÓN DEL REPARTO CONSTITUCIONAL DE LAS COMPETENCIAS POR PARTE DE LAS NORMAS COMUNITARIAS}

Aunque el ordenamiento nacional haya reconocido a las regiones amplios poderes en la ejecución de las normas comunitarias, esto no excluye la posibilidad de que actos normativos comunitarios incidan directamente sobre las competencias regionales. Esta afirmación es una consecuencia inmediata de la primacía del derecho comunitario sobre el derecho interno, incluso de rango constitucional, reconocido con el solo límite del necesario respeto a los principios supremos del ordenamiento, a partir de la sentencia n. 183 de 1973 de la Corte Costituzionale italiana: las "limitaciones de soberanían aceptadas para permitir la transferencia de algunas atribuciones a las instituciones comunitarias (art. 11 de la Constitución) comportan condicionamientos a las competencias del Estado o de las regiones ${ }^{21}$.

Es bien posible, por tanto, y no infrecuente, que normas comunitarias vengan a incidir sobre el ejercicio de las competencias regionales (fijadas además por normas constitucionales): "las competencias regionales son susceptibles de operar en la medida en que su contenido no viene a contrastar con las disposiciones y los límites introducidos por la normativa comunitaria", hasta el punto de que una competencia regional puede incluso devenir inoperante si la norma comunitaria cancela «el originario presupuesto sobre el que la competencia misma resultaba fundada" (sentencia n. ${ }^{\circ} 224$ de 1994) ${ }^{22}$.

Es posible, pues, que, con una intromisión todavía más fuerte, el derecho comunitario determine directamente a qué nivel, estatal o regional, deba ser desarrollada una actividad relevante sobre el plano europeo. Este fenómeno ha emergido con claridad en el momento de la elaboración de los programas integrados mediterráneos (PIM), por los cuales las normas comunitarias atribuían a las regiones funciones

21 Puede verse sobre esta cuestión CARTABIA, M.; OnIDA, V.: Le regioni e la Comunità europea, op. cit., 605 ss.

22 En el caso en cuestión las provincias autónomas de Trento y Bolzano lamentaban que el nuevo texto único en materia bancaria, adoptado en ejecución de directivas comunitarias, sustrajese su competencia, constitucionalmente reconocida, de autorizar la apertura de nuevas oficinas bancarias de relieve provincial: tal competencia, precisa la Corte, es incompatible con el principio de la «libertad de establecimiento" sancionado a nivel comunitario, y no puede por tanto permanecer inmutable frente a la nueva sistematización de la materia en el ámbito comunitario. 
que les eran extrañas en el marco nacional. La Corte Costituzionale reconoció la legitimidad de este método, afirmando que "los órganos comunitarios no están obligados a observar puntualmente la disciplina reguladora nacional y, en particular, el reparto de las competencias previsto incluso por norma de nivel constitucional, sino que pueden emanar, en el ámbito del derecho comunitario, disposiciones de diferente contenido: las cuales, sin embargo, (...) deben respetar los principios fundamentales de nuestro sistema constitucional, así como los derechos inalienables de la persona humana" (sentencia n. 399 de 1987). Esta jurisprudencia ha sido objeto de múltiples críticas, bien por la prevalencia reconocida al derecho comunitario derivado respecto al constitucional nacional, bien por la "nacionalización" del derecho comunitario (y la integración de los sistemas jurídicos) que vendría a realizarse en el momento en el cual viene asumido como parámetro del juicio de constitucionalidad, en lugar de las normas constitucionales sobre las competencias ${ }^{23}$.

Los sucesivos desarrollos del derecho comunitario han mostrado que si la Comunidad interviene por exigencia propia sobre el reparto de las competencias, lo hace principalmente en sentido opuesto al que había caracterizado lo sucedido con los PIM, privilegiando el momento estatal antes que el regional. La Corte, recientemente, retomando este tema en el ámbito de una importante (y ya citada) sentencia que constituye la summa de la propia jurisprudencia en la materia (sentencia n. 126 de 1996) ha confirmado una vez más que "las normas comunitarias pueden legítimamente prever, por exigencias organizativas propias de la Unión Europea, formas ejecutivas de sí mismas, y por tanto normativas estatales derogadoras del cuadro de normal distribución constitucional de las competencias internas, dejando a salvo el respeto de los principios constitucionales fundamentales e inderogables". Pero al mismo tiempo la Corte se ha detenido con más rigor que en el pasado sobre los casos en los cuales el derecho comunitario puede, legítimamente, modificar la disposición interna de las competencias. "Inútil decir, por lo demás, que esta situación no es la normal y debe

23 Ver, por ejemplo, Sorrentino, F.: Ammissibilità del conflitto e cammino comunitario della Corte. Un passo avanti e due indietro?, en Giur. cost., 1987, 2871; BALBONI, E.; PAPA, A.: Regolamenti comunitari e ripartizione costituzionale delle competenze: verso nuove frontiere? en Le regioni, 1988, 366 ss. Criticas semejantes se han dirigido a la sentencia n. 126 de 1996 por ANZON, A.: Le regioni in balia del diritto comunitario?, en Giur. cost., 1996, $1062 \mathrm{~s}$. De la misma autora, vid. Anche gli atti amministrativi comunitari possono redistribuire le competenze tra lo Stato e le regioni?, en Giur. cost., 1997, 936 s. 
por tanto derivarse de modo evidente de la normativa comunitaria, sobre la base de exigencias organizativas que razonablemente sean prioritarias en la misma Unión Europea. Así, por ejemplo, ha sucedido en los casos resueltos por esta Corte con las sentencias n. ${ }^{3} 38$ de 1993 y n. 389 de 1995 (en materia de controles veterinarios en las fronteras y de predisposición y ejecución de programas operativos en materia de pesca, respectivamente). En el primer caso, la concentración de funciones en la administración estatal ha sido justificada por la circunstancia de que la directiva comunitaria hacía referencia "a una actividad unitaria a nivel nacional en los Estados miembros" y en el segundo la misma solución organizativa, aun precisando el necesario entendimiento entre Estado y regiones se ha impuesto -en función de lo que resulta de la norma comunitaria-, bien por la requerida "unicidad" de la actividad programatoria y de intervención del Estado, bien por la previsión de la relativa «decisión única» por parte de la Comisión Europea, que tiene como destinatarios los estados como tales y que concierne a la aprobación de propuestas nacionales".

En sentido contrario, precisamente en la sentencia n. 0126 de 1996 no se ha considerado suficiente para justificar una alteración de la disposición constitucional de las competencias (como la asignación al Ministro de agricultura de las funciones de control en materia de agricultura biológica) la referencia, contenida en el Reglamento comunitario al que el Decreto legislativo estatal censurado daba ejecución, a "una autoridad encargada del reconocimiento y de la vigilancia” de los organismos reconocidos, para los países en los cuales, como en Italia, tal control fuese confiado a organismos privados. En efecto, la Corte no advierte entre las exigencias de las que la normativa comunitaria es expresión, razones que justifiquen la opción centralizadora nacional que, precisamente en cuanto que opción nacional y no requerida a nivel comunitario, aparece constitucionalmente ilegítima.

\section{FORMAS DE PARTICIPACIÓN (DIRECTA E INDIRECTA) DE LAS REGIONES EN LA FORMACIÓN DE LA VOLUNTAD COMUNITARIA}

Las normas comunitarias, por tanto, ya sea en cuanto que propongan principios que las regiones están llamadas a ejecutar, ya en cuanto que pueden alterar el modelo constitucional de distribución de competencias, inciden profundamente sobre la autonomía regional, condicionando su modo de ejercicio y determinando su dimensión. 
¿Qué medios conservan las regiones para la defensa de la propia autonomía? Ciertamente no el juicio de constitucionalidad, "a causa del peculiar régimen al cual están sujetos los actos de las instituciones comunitarias, controlables a la luz del derecho interno solamente si entran en conflicto con los principios supremos de la Constitución". Como la Corte Costituzionale ha afirmado, "para impedir que en sede comunitaria vengan lesionadas las propias atribuciones, sobre las regiones recae la carga de actuar y hacerse presentes antes de que los programas del Estado se conviertan en actos de la Comunidad, asumiendo el valor jurídico propio de éstos" (sentencia n. 93 de 1997). En otros términos, la vía que las regiones pueden seguir para defender las competencias propias, frente a actos normativos comunitarios, según lo que señala la Corte Costituzionale, es una vía preventiva, la de la participación en la formación del derecho comunitario.

Tal participación en la llamada "fase ascendente" del proceso de integración europea se articula: a) en la participación directa de las regiones en órganos y procedimientos de la Unión Europea, y b) en la participación indirecta, a través de la presencia regional en las sedes nacionales en las que se forma la posición que el Estado sostendrá, después, a nivel comunitario ${ }^{24}$.

En cuanto a las relaciones directas de las regiones con las instituciones comunitarias, se ha asistido a una evolución del cuadro normativo que, partiendo de una asimilación de las relaciones con la Comunidad Europea con otro tipo de relaciones internacionales, ha llegado a un tipo de disciplina reguladora sui generis, que permite a las regiones un mayor margen de maniobra.

El d.P.R. n.o 616 de 1977, en su artículo 4, apartado 1, reservaba al Estado, incluso en materias regionales, las funciones que se referían a las relaciones con la Comunidad europea. A las regiones les quedaba sólo la posibilidad, con base en el apartado 2 del mismo artículo, de desarrollar una actividad de tipo promocional en el exterior, también en las materias de competencia propia, previo acuerdo con el gobierno. Hará falta esperar hasta 1994 (ley $n . .146$ de 1994, art. 60) para que el legislador disponga que el acuerdo no es necesario para lo que se refiere a las relaciones entre las regiones y los organismos comunita-

24 Ver, entre otros muchos, Tizzano, A.: La partecipazione delle regioni al processo di integrazione comunitaria: problemi antichi e nuove prospettive, en Le regioni, 1992, 603 ss.; Strozzı, G.: Partecipazione delle regioni all'elaborazione delle politiche comunitarie e loro competenza all'attuazione degli atti comunitari alla luce della legge n. ${ }^{\circ} 86$ del 1989, en Riv. it. dir. pubbl. com., 1992, 111 ss. 
rios. A pesar de que, todavía en 1997, la Corte Costituzionale hubiese declarado inadmisible la petición regional de abrogar, mediante referéndum, la referencia a la Comunidad europea en el apartado 1 del artículo 4 del d.P.R. n. ${ }^{\circ} 616$ de 1977 , sosteniendo que "el conjunto de las funciones que el Estado está llamado a ejercitar en las relaciones con la Comunidad europea no puede ser modificado y globalmente asumido por las regiones, violando el principio de unidad e indivisibilidad de la República" (sentencia n. ${ }^{\circ} 20$ de 1997), la normativa más reciente (art. 1, apartado 4, letra e) de la ley n. 59 de 1997 y art. 2 del decreto legis-

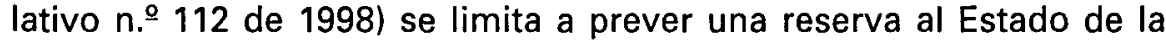
"coordinación de las relaciones con la Unión europea», introduciendo así una neta diferenciación con la materia de los "asuntos exteriores" que permanece de modo estable en manos del Estado.

La nueva disciplina que regula la materia del poder exterior de las regiones (d.P.R. 31 de marzo de 1994, art. 4) ha permitido, pues, a éstas tener libremente, sin deber dirigir ninguna comunicación al gobierno, relaciones con las oficinas, organismos, e instituciones comunitarias, comprendido el comité consultivo, en relación a cuestiones que directamente les afecten, comenzándose a construir un cuadro normativo dentro del que se sitúan iniciativas que las regiones ya llevaban asumiendo espontáneamente desde hacía tiempo.

El ordenamiento italiano prevé hoy dos principales modalidades a través de las cuales las regiones pueden hacerse presentes ante las instituciones comunitarias, que se añaden así a los instrumentos participativos previstos por el derecho comunitario, como el Comité de las Regiones.

Ante todo, las regiones pueden crear ante las sedes de las instituciones de la Unión europea oficinas de enlace propias o comunes, que se encargan de las relaciones con las instituciones comunitarias (ley n. 52 de 1996, art. 58) ${ }^{25}$. Tales oficinas pueden ser también comunes con otras regiones o entes pertenecientes a la Unión europea, en el ámbito de la cooperación transfronteriza o de acuerdos internacionales (art. 13, apartado 11, ley n. .9128 de 1998) ${ }^{26}$.

25 Ver sobre este asunto Boccl, V.E.: /I "potere estero" delle regioni. I/ caso dell'ufficio di collegamento della Regione Toscana, en Le istituzioni del federalismo, 2000, 63 ss.; BADIELLO, L.: Ruolo e funzionamento degli uffici regionali europei a Bruxelles, ibidem, 89 ss.

26 Antes de aprobarse esta disposición, la Corte Costituzionale (sentencia n. 428 de 1997) había anulado el acto con el que la provincia de Bolzano había creado la propia sede en Bruselas conjuntamente con el Land del Tirol, por cuan- 
Además, de la representación permanente de Italia ante la Unión europea forman parte cinco funcionarios regionales (art. 58 ley n. -52 de 1996, sustituido por el art. 11, apartado 9, ley n. -128 de 1998).

El instrumento más relevante de intervención de las regiones en la fase ascendente se ha desarrollado sin embargo en el campo de la participación indirecta, y está constituido por la Conferencia Estadoregiones.

Este órgano mixto, principal ámbito de acuerdo y colaboración entre el Estado y las regiones, creado en 1983 y que ha visto una continua expansión de sus tareas, reviste un importante papel en la materia desde 1989, cuando fue prevista (art. 10 de la ley $n . .86$ de 1989) una específica "sesión comunitaria" de la Conferencia. Con base en la normativa hoy vigente ${ }^{27}$, la Conferencia se convoca al menos dos veces al año por el presidente del Consejo de Ministros, que la preside, también a petición de las regiones, con el fin de:

a) acordar con las exigencias regionales las líneas de la política nacional relativa a la elaboración de los actos comunitarios;

b) expresar el parecer sobre los criterios y modalidades para conformar el ejercicio de las funciones regionales para observación y cumplimiento de las obligaciones comunitarias;

c) expresar el parecer sobre el proyecto anual de «ley comunitarian" 28

d) designar los componentes regionales en el seno de la representación permanente italiana ante la Unión europea.

La cuestión de las relaciones entre las regiones y el derecho comunitario ha sido afrontada también por los muchos proyectos de

to consideraba que afectaba a la esfera de la política exterior: como tal habria debido ser comunicado al gobierno. Esto, precisa la Corte, "no pone en discusión el desarrollo, en el contexto de los ordenamientos en Europa y en el ámbito de las mismas instituciones comunitarias, del papel de las comunidades regionales y locales".

27 Se entrelazan y superponen, además del art. 10 de la ley n. 86 de 1989 , modificado por el art. 13, apartado 7, de la ley n. 128 de 1998, también el art. 5 del decreto legislativo $n .9281$ de 1997, que dicta la nueva disciplina que regula la conferencia, y el artículo 58, apartado 2-bis de la ley n. 52 de 1996.

${ }_{28}$ La uley comunitaria" es una ley de cadencia anual, prevista por el art. 2 de la ley n. 86 de 1989, con la cual se da ejecución al derecho comunitario, bien directamente, bien a través de delegación legislativa y confiriendo potestad reglamentaria al gobierno. Esta ley constituye el instrumento principal a través del cual el ordenamiento italiano se adecua al derecho comunitario. 
revisión del título $\mathrm{V}$ de la Constitución elaborados en el curso de los años noventa, todos dirigidos a insertar en la Constitución, que actualmente calla en este punto, disposiciones incluso extremadamente detalladas. El texto aprobado el 8 de marzo de 2001 por el Parlamento (que entrará en vigor si se aprueba en referendum) prevé que:

a) corresponde al Estado la potestad legislativa exclusiva en materia de relaciones del Estado con la Unión europea;

b) se considera entre las materias de legislación concurrente (a la italiana) la de las relaciones de las regiones con la Unión europea;

c) en las materias de su competencia, las regiones participan en las decisiones dirigidas a la formación de los actos normativos comunitarios y proveen la ejecución de los actos de la Unión europea, respetando las normas de procedimiento establecidas a través de ley del Estado, que regula las modalidades de ejercicio del poder sustitutorio en caso de incumplimiento.

Un proyecto, como se ve, dirigido no a introducir radicales innovaciones, sino más bien a transponer a nivel constitucional el cuadro de relaciones Estado-regiones-Unión Europea que ha tomado forma en los años noventa, por la acción conjunta de las reformas legislativas y las sentencias de la Corte Costituzionale. 